\title{
THREE CASES OF CHRONIC TUBERCULOUS CHOROIDITIS, WITH A COMMENT ON THE COMPLICATION, OPTIC NEURITIS
}

\author{
BY \\ J. D. Cummins \\ DUBLIN
}

1. H.V.T., a secondary teacher, 24 years of age, visited me in August, 191\%, complaining that, during the previous year, he had often noticed a transitory blurring of the vision of his left eye. He had never had any definite illness, but had been a delicate child and was far from being a robust young man. Apart from occasional blurring of the vision of his left eye, there was no other symptom.

With optical correction, the vision of the right eye was $6 / 9$, and the vision of the left one 6/12. The right fundus was normal. There were in the left eye, optic neuritis, and, at the periphery of the fundus, above and below, sclerosis of the choroidal vessels. Wassermann reaction negative. Urine free from sugar, albumen and casts. The left visual field was of good size. There was no interlacing of the blue field with the red or green. An examination of the central nervous system and of the accessory nasal sinuses did not reveal anything amiss. A tonic plan of treatment was instituted.

In the following January, the vision of the left eye was full and the optic neuritis had subsided. Fifteen months later, I noted "L.E.V. 6/12; extensive patchy choroidal atrophy, and an illdefined greyish prominence, near the lower nasal border of the disc-distinct arching of vessel over prominence (T.B.)."

Nearly three years passed before I saw the patient again. In February, 1922, the visual acuity of each eye, with optical correction, was $6 / 9$. But the fundi were greatly changed. In the right eye, normal at the last examination (March, 1919), there was a slightly prominent, ill-defined area near the lower border of disc, and, elsewhere, irregularly-shaped and variously-sized areas of pigment were scattered through the choroid, with patches of choroidal sclerosis between them. At the periphery, specks of pigment were seen in the retina. In the left eye the same sort of picture was to be seen, but without any raised focus. The prominent nodule, over which had arched the inferior nasal branch of the central artery, was now flat and speckled with pigment. One could not but be astonished at the apparent want of correspondence between the extensive choroidal changes and the excellent visual acuity. 
My latest observation of the patient was in April of last year. The visual acuity of each eye was still 6/9. The nodule that had been seen near the lower border of the right disc had disappeared. Apparently the left optic neuritis was of such short duration, that its subsidence without secondary atrophy of the nerve head was possible:

2. B.R., a young woman of 28 years of age; came under my observation six years ago. She was, then, suffering from a mild attack of phlyctenular conjunctivitis in one eye. For more than two years following her seventh birthday (she had been a healthy youngster until then) the patient was very ill. During those years the lymphatic glands in the neck became enlarged and underwent suppuration. The child's general health was grievously impaired; she dwindled into a weak emaciated figure. Contrary to expectation improvement set in, and gradually, the child's health was restored.

At my first examination, the visual acuity of the right eye was $6 / 12$, that of the left one $6 / 60$. The latter eye was known to have been defective for years. Each choroid exhibited numerous sharply-outlined patches of atrophy. Most of the atrophic areas were about one-half of the disc's diameter in size, and some of them had rims of pigment. There were specks of pigment in the retinae. The left disc looked pale when compared with the right one.

Rest, a nutritious diet, change of air and scene soon brought about the disappearance of the phlyctenular conjunctivitis. I saw the patient three or four times during the next two years. The ophthalmoscopic picture remained unchanged. The right eye retained a visual acuity of 6/9. In January, 1923, I saw the patient again. Four years had elapsed since the last examination. Now, for the first time, the patient complained that her good eye was failing. In the evening time it was not possible to read print that she had been reading during the day. Right eye V. 6/18, left eye V. 2/60. No change in the earlier noted appearances of the fundi was observed.

3. J.B., a frail young woman of 22 years of age, complained that her right eye had been a delicate one all her life. There had been, from time to time, attacks of inflammation in it. One month ago, an attack had set in.

The right eye exhibited slight ciliary injection. The cornea was diffusely hazy from scattered nebulae, and a few deep bloodvessels were present. The iris, which responded well to atropin, showed a single posterior synechia and three tiny pale nodules at the pupillary margin. There was diffuse choroidal atrophy with wide areas of depigmentation, and, near the disc's margin, 
two ill-defined pale areas were seen, over the larger of which a vessel was clearly arched. Disc pale. Visual acuity, hand movements. The distinctness of the indirect image seemed to indicate that the corneal opacities were of little account in determining the very great visual impairment. Left eye V. 6/9. No pathological appearance was observed in this eye. Wassermann reaction negative. This case was a good clinical illustration of the predilection of the tubercle bacillus for the uveal tract, including the uveal stratum (in a morphological sense) of the cornea, as the presence of the deep blood-vessels proclaimed.

It is not to trace the familiar path, leading from disseminated choroiditis through atrophy of the inflamed foci and, later, by the way of pigmentation and atrophy of the retina, with concomitant nyctalopia, to permanent loss of visual acuity, that I record these cases. My purpose is to supply some support, imperfect and inadequate though it be, for a suggestion that I am about to make.

There occurred in the first case a transient unilateral optic neuritis. There was in the second case marked inequality of the visual impairment of the eyes, without a refractive error or a striking difference in the extent of involvement of the choroids to account for it. But there was pallor of the disc on the more impaired side. In the third case, in which, too, a pale disc was seen, I was unprepared for the almost complete annihilation of vision. The earlier cases had exhibited, in three of the four eyes, surprisingly good visual acuity with extensive choroidal changes. Perhaps the almost blind eye of Case 3 and the more impaired one of Case 2 owed their loss, in part, to a secondary atrophy following optic neuritis.

Out of these cases has come the notion that the optic neuritis of Case 1 and the hypothetical optic neuritis of Cases 2 and 3 were dependent upon a circumscribed tuberculous meningitis of the sheaths of the optic nerve. Infection could travel from the choroid by way of the perichoroidal space outward along the vessels, especially the venae vorticosae, to Tenon's space and thence to the lymph spaces which surround the optic nerve. At least there is no anatomical objection to the suggestion. And if it be valid, may not some cases of unilateral optic neuritis be dependent upon an unrecognized or hidden tuberculous focus in the choroid? It is no more than a guess.

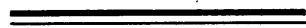

